\title{
Plasma atrial natriuretic polypeptide concentrations during and after reversion of paroxysmal supraventricular tachycardias
}

\author{
JOHN R OLIVER, NICHOLAS TWIDALE, CAROL LAKIN, MICHAEL CAIN, \\ ANDREW M TONKIN
}

From the Department of Medicine, Flinders Medical Centre, South Australia

SUMMARY Plasma concentrations of immunoreactive atrial natriuretic polypeptide were raised in 22 of 23 patients with paroxysmal supraventricular tachycardia and in all seven patients with atrial $\infty$ flutter. Plasma concentrations of atrial natriuretic polypeptide rose soon after the onset of $\frac{2}{2}$ supraventricular tachycardia. A sample taken 30 minutes after reversion to sinus rhythm $\vec{T}$ (pharmacological or non-pharmacological) showed a significant fall in 19 of the 23 patients with paroxysmal supraventricular tachycardia and all seven patients with atrial flutter.

Because atrial natriuretic polypeptide has powerful natriuretic and diuretic properties, an increase may contribute considerably to the polyuria that is often associated with episodes of supraventricular tachycardia.

Mammalian atrial tissue has been shown to contain secretory-like storage granules with characteristics similar to those of endocrine peptide secretory cells. ${ }^{12}$ These granules were shown to contain a polypeptide hormone, which is first synthesised as a 151 amino acid prohormone. ${ }^{34}$ The prohormone is further processed to several smaller peptides, one of which is $\alpha$ natriuretic polypeptide, a 28 amino acid polypeptide with potent natriuretic, diuretic, and vasorelaxant properties. ${ }^{5-7}$

The physiological role of atrial natriuretic polypeptide, or indeed any of the post-translational products, is unknown; however, there is a considerable body of evidence to suggest that this peptide may help to maintain sodium ion and water balance and modulate the renin-angiotensin aldosterone system. ${ }^{8}$ A major stimulus for the release of atrial natriuretic polypeptide into blood seems to be atrial distension produced by volume loading or increased dietary intake of sodium ion..$^{10}$

Paroxysmal supraventricular tachycardias are often associated with considerable polyuria and reports of raised concentrations of plasma atrial natriuretic polypeptide in such patients suggest that

Requests for reprints to Dr John R Oliver, Department of Medicine, Flinders Medical Centre, Bedford Park 5042, South Australia, Australia.

Accepted for publication 8 December 1987 this substance may account for the combined diuresis and natriuresis. ${ }^{11-13}$

We measured plasma concentrations of atrial natriuretic polypeptide before and after reversion to sinus rhythm in patients with paroxysmal supraventricular tachycardia and those with atrial fibrillation or flutter.

\section{Patients and methods}

\section{PATIENTS}

This study was carried out within the guidelines set down by the National Health and Medical Research Council of Australia and was approved by the $\frac{\rho}{9}$ institute's human ethics advisory committee.

We studied twenty three patients admitted to our casualty department with paroxysmal supraven- N tricular tachycardia (18 women and 5 men, aged 1781 (mean 53) years). Diagnosis was confirmed by 120 lead electrocardiography which showed a regular, $\omega$ narrow QRS tachycardia in all 23 patients. Patients with acute or chronic congestive cardiac failure were specifically excluded.

In addition, we studied seven patients (five men and two women (mean age 60) with atrial fibrillation or flutter and five control patients (three men and two women (mean age 50)) without arrhythmias who had $\stackrel{?}{\circ}$ had intravenous lines inserted in the casualty depart- $\triangle$ ment for other indications.

Renal function was assessed in all patients. Plasma 
creatinine concentrations were within the normal range $(0 \cdot 06-0 \cdot 12 \mathrm{mmol} / \mathrm{l})$ in all but two patients $(0 \cdot 14$ and $0.21 \mathrm{mmol} / \mathrm{l})$.

Fifteen patients were receiving concomitant medication when they were studied. This included a $\beta$ blocker in one, $\beta$ blocker plus digoxin in two, digoxin alone in one, quinidine in two, verapamil in one, diuretic agents in three, theophylline in one, thyroxine in two, and non-steroidal antiinflammatory drugs in two.

A first blood sample was taken after insertion of a peripheral intravenous line and before attempted reversion and a second sample was taken 30 minutes after reversion to sinus rhythm.

BLOOD COLLECTION AND RADIOIMMUNOASSAY

OF ATRIAL NATRIURETIC POLYPEPTIDE IN

PLASMA

Blood collection and extraction

Venous blood $(10 \mathrm{ml})$ was collected into a chilled tube containing edetic acid and aprotinin (10 000 units; Bayer, Australia). We took care to avoid haemolysis, which causes loss of immunoreactive atrial natriuretic polypeptide in plasma. Plasma was separated immediately by centrifugation, snap frozen, and stored at $-20^{\circ} \mathrm{C}$ until assay.

\section{Extraction of plasma}

Plasma $(1 \mathrm{ml})$ was extracted overnight at $4^{\circ} \mathrm{C}$ with $1.8 \mathrm{ml}$ acidified ethanol (95: 5 parts of $95 \%$ ethanol: $6 \mathrm{~mol} / 1$ acetic acid) followed by centrifugation, and lyophilisation of the supernatant. The dried extract, equivalent to $1.0 \mathrm{ml}$ of plasma, was reconstituted with $0.50 \mathrm{ml}$ of assay buffer (radioimmunoassay section) and assayed for atrial natriuretic polypeptide.

The efficiency of the extraction procedure was determined for each patient's sample by the addition of radiolabelled human $\alpha$ atrial natriuretic polypeptide to a separate $1 \mathrm{ml}$ volume of patient's plasma. This plasma was extracted as described above. After reconstitution in assay buffer $(0.50 \mathrm{ml})$ a $200 \mu \mathrm{l}$ volume was taken and its radioactive content measured and recovery was estimated. Recovery of radiolabelled human $\alpha$ atrial natriuretic polypeptide from plasma samples from both the controls and the patients was $78(6) \%$ (mean (SEM)).

\section{Radioimmunoassay of atrial natriuretic polypeptide}

Assay buffer.-For all procedures in the assay we used $0.05 \mathrm{~mol} / 1$ sodium phosphate buffered saline pH 7.4 containing aprotinin $(250 \mathrm{U} / \mathrm{ml})$, edetic acid $(0.01 \mathrm{~mol} / \mathrm{l}), 0.25 \mathrm{~g} \%$ bovine serum albumin (Sigma Chemical, radioimmunoassay grade), and thiomerosal $(0.6 \mathrm{mmol}$ ) (Sigma Chemical, as a preservative).
Specificity and characterisation of antiserum.Antiserum to atrial natriuretic polypeptide 1-28 was raised in sheep after conjugation of synthetic human $\alpha$ atrial natriuretic polypeptide $1-28$ to bovine thyroglobulin (Sigma Chemical USA) with ethylcarbodiimide (Pierce Chemicals, USA). The antiserum cross reacted to an equal degree with atriopeptins I, II, III, but it did not cross react with cardiodilatin 1-16, angiotensin II, vasopressin, oxytocin, neuropeptide $\mathrm{Y}$, somatostatin, $\beta$ endorphin, leu and met enkephalins and dynorphins 1-8 and $1-13$.

We used the MK model extended least squares non-linear curve fitting program to analyse antibody binding affinity. Two binding sites were found: the first had a dissociation constant $(\mathrm{Kd})$ of $37.58 \mathrm{pmol} / 1$ and affinity constant $(\mathrm{Ka})$ of $2.7 \times 10 \mathrm{l} / \mathrm{pmol}$ and the second a $\mathrm{Kd}$ of $122.5 \mathrm{pmol} / \mathrm{l}$ and $\mathrm{Ka}$ of $0.08 \times$ $10 \mathrm{l} / \mu \mathrm{mol}$.

Radioimmunoassay was carried out in $10 \times 75 \mathrm{~mm}$ borosilicate glass tubes under non-equilibrium conditions at $4^{\circ} \mathrm{C}$. Duplicate volumes $(0.20 \mathrm{ml})$ of the plasma extract were incubated with $100 \mu \mathrm{l}$ of sheep antiserum to human $\alpha$ atrial natriuretic polypeptide (final concentration 1:6000), followed by a further two day incubation, after the addition of $100 \mu \mathrm{l}$ of (3$\left[{ }^{125} I\right]$ iodotyrosyl 28$) \alpha$ atrial natriuretic polypeptide (5000 counts/min equivalent to $1-2$ pg tracer mass) (Amersham, Australia). Synthetic human $\alpha$ atrial natriuretic polypeptide was used to generate a standard curve over the range $2-1000 \mathrm{pg} /$ tube.

Bound and free atrial natriuretic polypeptide were separated by the addition of $100 \mu \mathrm{l}$ of carrier sheep serum (diluted 1:250) and $100 \mu \mathrm{l}$ of donkey antisheep immunoglobulin serum (diluted 1:5) followed by incubation at room temperature for three hours and centrifugation. The pellet was counted in a NEN 1600 gamma counter (Nuclear Enterprises). Standards were set up in triplicate in the presence of $0.20 \mathrm{ml}$ of an extract of charcoal stripped plasma (hormone free) so as to reproduce the assay conditions used for the patient plasma samples. Concentration of plasma atrial natriuretic polypeptide was determined from the standard curve, plotted as the logit-log of the ratio of bound counts of unknown to bound counts of the zero standard versus concentration ( $\mathrm{pg} /$ tube). The standard curve was linear over the range 10 to $600 \mathrm{pg} /$ tube and the sensitivity of the assay was $2 \mathrm{pg} /$ tube ( 2 from the mean $\pm \mathrm{SD}$ of the zero standard). The intra and inter assay variability were 8 and $15 \%$ respectively.

Characterisation of plasma atrial natriuretic polypeptide measured by radioimmunoassay.-Plasma samples collected before and after reversion were pooled separately, extracted as above, and the dried 
extracts were analysed by high pressure liquid chromatography on a $\mathrm{C} 18$ reverse phase column and with an acetonitrile linear gradient elution profile. Analysis of the column eluant showed one major peak of immunoreactivity for both the plasma samples that coincided with the elution profile of the synthetic human $\alpha$ atrial natriuretic polypeptide (results not shown).

The plasma extracts were further characterised by serial dilution experiments. Pooled extracts of plasma obtained before and after reversion diluted in parallel with the synthetic human $\alpha$ atrial natriuretic polypeptide standard (results not shown).

Concentration of atrial natriuretic polypeptide in controls.-Atrial natriuretic polypeptide was measured in blood samples from 34 normotensive healthy volunteers ( 14 men, 20 women) with normal dietary intake of sodium and electrolyte status which were treated and extracted as described above. Subjects remained seated for 15 minutes before a blood sample was taken between 9 am and $10.30 \mathrm{am}$. The upper and lower limits of the normal range were $70 \mathrm{pg} / \mathrm{ml}$ and $4 \mathrm{pg} / \mathrm{ml}$ respectively and no sex dependent differences were found (men 36 (14) pg/ $\mathrm{ml}$, women $33(16) \mathrm{pg} / \mathrm{ml}$ ) (mean (SEM)).

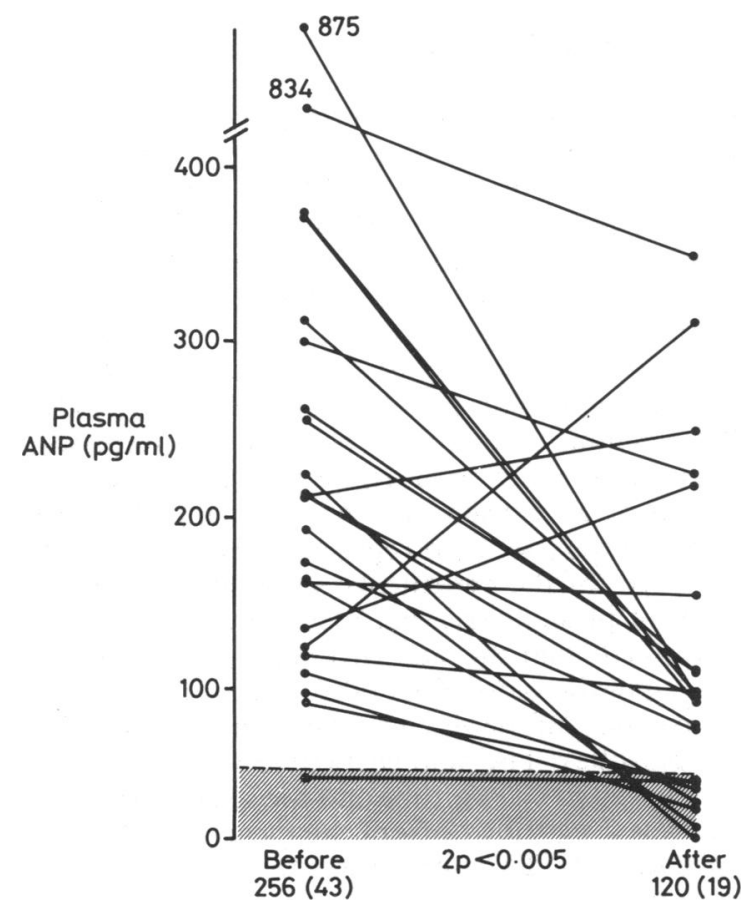

Fig 1 Plasma concentration (mean (SEM)) of atrial natriuretic polypeptide ( $A N P)(p g / m l)$ before and 30 minutes after reversion in 23 patients with paroxysmal supraventricular tachycardia. The normal range is also shown.

\section{Results}

Figure 1 shows plasma concentrations of atria殿 natriuretic polypeptide before and after reversion te sinus rhythm in the 23 patients with paroxysmaE supraventricular tachycardia. During paroxysma supraventricular tachycardia 22 of 23 patients hadp atrial natriuretic polypeptide concentrations above the upper limit for normal subjects in this laboratory. $(70 \mathrm{pg} / \mathrm{ml})$. In one patient plasma atrial natriuretic polypeptide was within the normal range and did not change after reversion. Paroxysmal supraventricularo tachycardia was converted to sinus rhythm by intravenous verapamil (1-20 mg) in 16 patients intravenous digoxin $(250-500 \mu \mathrm{g})$ in one, vaga manoeuvres in three, or a combination of these in three. In 19 patients concentrations of plasma atriapo natriuretic polypeptide fell 30 minutes aftes reversion, in five to within the normal range. The mean concentration of plasma atrial natriuretio polypeptide was $256(43) \mathrm{pg} / \mathrm{ml}$ before reversion and 120 (19) $\mathrm{mg} / \mathrm{ml} 30$ minutes after reversiono ( $2 \mathrm{p}<0.005$ by paired Student's $t$ test). The fall inpo the concentration of atrial natriuretic polypeptider seemed to be independent of the mode of reversion of paroxysmal supraventricular tachycardia.

There was a weak inverse relation between the rate of paroxysmal supraventricular tachycardia $\left(140-\frac{D}{D}\right.$ 220 beats $/ \mathrm{min}$ ) and plasma concentrations of atria natriuretic polypeptide $(r=-0.45, p=0.017$ by

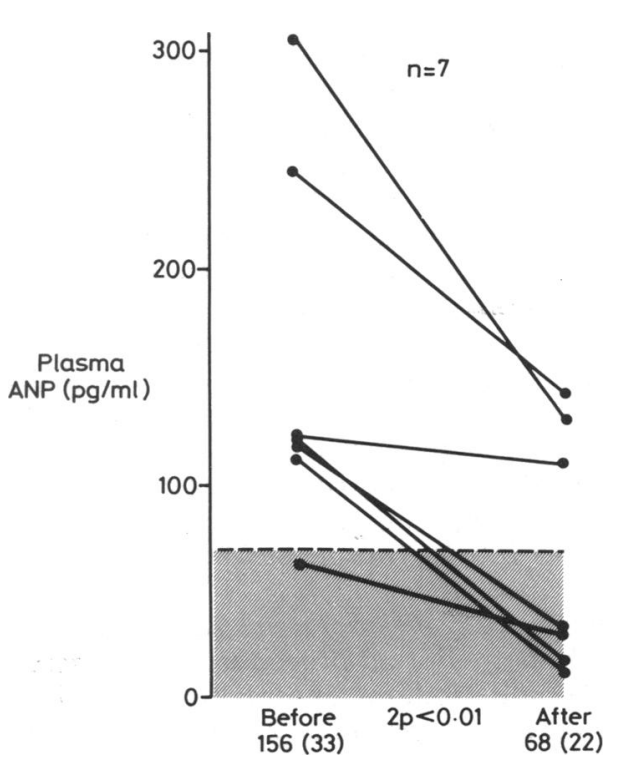

Fig 2 Plasma concentration (mean (SEM)) of atrial natriuretic polypeptide $(A N P)(p g / m l)$ before and 30 minutes after reversion in seven patients with atrial fibrillation or flutter. The normal range is also shown. 
Pearson's test). The duration of paroxysmal supraventricular tachycardia (10 min-3 days) had no apparent effect on plasma atrial natriuretic polypeptide concentrations; one patient had considerably raised plasma atrial natriuretic polypeptide (84 $\mathrm{pg} / \mathrm{ml}$ ) with paroxysmal supraventricular tachycardia lasting only 10 minutes.

In the seven patients with atrial fibrillation or flutter, plasma concentrations of atrial natriuretic polypeptide were raised before reversion was attempted (156 (33) $\mathrm{pg} / \mathrm{ml})$ and fell after reversion (68 (22) $\mathrm{pg} / \mathrm{ml}$ ) (fig 2).

\section{Discussion}

Our results show that patients with supraventricular tachycardia, particularly paroxysmal supraventricular tachycardia, and atrial fibrillation or flutter have considerably higher plasma concentrations of atrial natriuretic polypeptide than healthy controls. These results are consistent with earlier studies of small numbers of patients and animal studies. ${ }^{13-19}$ Given that atrial natriuretic polypeptide has natriuretic and diuretic properties, the increase may account for the polyuria reported in patients with supraventricular tachycardias. ${ }^{12021}$ Others have suggested that the polyuria may be caused by suppressed vasopressin release ${ }^{2122}$; however, such a mechanism does not account for the striking natriuresis associated with this condition. ${ }^{20}$

Plasma concentrations of atrial natriuretic polypeptide may rise early after the onset of paroxysmal supraventricular tachycardia and remain raised for prolonged periods of tachycardia, independent of clinical indices of left ventricular failure. The weak inverse relation between the rate of paroxysmal supraventricular tachycardia and plasma concentrations of atrial natriuretic polypeptide remains unexplained. One possible explanation is that the atrial cardiocyte becomes fatigued and supplies of atrial natriuretic polypeptide are exhausted. This would be an unusual phenomenon in endocrine cells but would be consistent with the fall in concentrations of atrial natriuretic polypeptide during tachycardia in one of the patients with atrial flutter (119 $\mathrm{pg} / \mathrm{ml}$ to $44 \mathrm{pg} / \mathrm{ml}$ ) that occurred without a change in rate of tachycardia and before reversion was attempted.

Although atrial pressure increases in this type of tachycardia and may act as the stimulus for secretion of atrial natriuretic polypeptide, ${ }^{11}$ alternative intrinsic mechanism(s) associated with the arrhythmias could also mediate release of atrial natriuretic polypeptide. Further studies will be required to elucidate the mechanism(s) responsible.

In conclusion, supraventricular tachycardia (and paroxysmal supraventricular tachycardia in particular) are associated with raised concentrations of plasma atrial natriuretic polypeptide that fall rapidly and apparently independently of the mode of reversion whether this is pharmacological or nonpharmacological.

We thank Dr R Murphy for high pressure liquid chromatography analysis. This work was carried out with part support from the National Health and Medical Research Council of Australia.

\section{References}

1 Jamieson JD, Palade GE. Specific granules in atrial muscle cells. J Cell Biol 1964;23:151-72.

2 de Bold AJ, Raymond J, Benescome SA. Atrial specific granules of the rat heart, light microscopic staining and histochemical reaction. J Histochem Cytochem 1978;26:1094-102.

3 Oikawa S, Imai M, Veno A, et al. Cloning and sequence analysis of cDNA encoding a precursor for human atrial natriuretic polypeptide. Nature 1984;309: 724-6.

4 Lewicki J, Greenberg B, Yamanaka M, et al. Cloning, sequence analysis and processing of the rat and human atrial natriuretic peptide precursors. Fed Proc 1986;45:2086-90.

5 de Bold AJ, Borenstein HB, Veress AT, Sonnenberg HA. A rapid and potent natriuretic response to intravenous injection of atrial myocardial extract in rats. Life Sci 1981;28:89-94.

6 Kuribayashi T, Nakazato $M$, Tanaka $M$, et al. Renal effects of human-atrial natriuretic polypeptide. $N$ Engl J Med 1985;312:1456-7.

7 Currie MG, Geller DM, Cole BR, et al. Bioactive cardiac substances: potent vasorelaxant activity in mammalian atria. Science 1983;221:71-3.

8 Laragh JH. Atrial natriuretic hormone, the renin-aldosterone axis, and blood pressure-electrolyte homeostasis. N Engl J Med 1985;313:1330-40.

9 Rascher W, Tulassay T, Lang RF. Atrial natriuretic peptide in plasma of volume loaded children with chronic renal failure. Lancet 1985;ii:303-5.

10 Sagnella GA, Markandu ND, Shore AC, MacGregor GA. Effects of changes in dietary sodium intake and saline infusion on immunoreactive atrial natriuretic peptide in human plasma. Lancet 1985;ii:1208-11.

11 Wood P. Polyuria in paroxysmal tachycardia and paroxysmal atrial flutter and fibrillation. $\mathrm{Br}$ Heart $J$ 1963;25:273-82.

12 Yamaji $T$, Ishibashi $M$, Nakaoka $H$, Imataka $K$, Amano M, Fujii J. Possible role for atrial natriuretic peptide in polyuria associated with paroxysmal atrial arrhythmias. Lancet 1985;i:1211.

13 Schiffrin EL, Gutkowska J, Kuchel O, Cantin M, Gennest J. Plasma concentration of atrial natriuretic factor in a patient with paroxysmal atrial tachycardia. N Engl J Med 1985;312:1196-7.

14 Tikkanen I, Metsarinne K, Fyhrquist F. Atrial 
natriuretic peptide in paroxysmal supraventricular tachycardia. Lancet 1985;ii:40-1.

15 Koller PT, Nichlas JM, DiCarlo LA, Shenker Y, Grekin RJ. Marked elevation of plasma atrial factor during paroxysmal supraventricular tachycardia [Abstract]. Circulation 1985;72(suppl III):102.

16 Kojima $S$, Akabana $S$, Ohe $T$, et al. Plasma atrial natriuretic polypeptide and polyuria during paroxysmal tachycardia in Wolff-Parkinson-White syndrome patients. Nephron 1986;44:249-52.

17 Anderson JV, Gibbs JS, Woodruff PIW, Creco C, Rowland E, Bloom SR. The plasma atrial natriuretic peptide response to treatment of acute cardiac failure, spontaneous supraventricular tachycardia and induced re-entrant tachycardia in man. $J$ Hypertens 1986;suppl 2:S137-41.

18 Anderson JV, Bloom SR. Physiological and path- ological stimuli releasing atrial natriuretic peptide in humans. In: Brenner BM, Laragh JR, eds. $c$. Biologically active atrial peptides, Vol. 1. New York: Raven Press, 1987:41-8.

19 Rankin AJ, Courneya CA, Wilson N, Ledsome JR. Tachycardia releases atrial natriuretic peptide in the anesthetised rabbit. Life Sci 1986;38:1951-7.

20 Kinney MJ, Stein RM, DiScala VA. The polyuria of $\mathbb{D}$ paroxysmal atrial tachycardia. Circulation 1974; 50:429-35.

21 Boykin J, Cadnapaphornchai P, McDonald K, Schrier $\vec{\circ}$ R. Mechanism of diuretic response associated with atrial tachycardia. Am J Physiol 1975;229:1486-91.

22 Canepa-Anson R, Williams M, Marshall J, Mitsuoka T, Lightman S, Sutton R. Mechanism of polyuria and natriuresis in atrioventricular nodal tachycardia. $B r$ G Med J 1984;289:866-8. 